\title{
Influence of the weld thermal cycle on the grain structure of friction-stir joined 6061 aluminum alloy
}

\author{
Alexander Kalinenko, Igor Vysotskiy, Sergey Malopheyev, Sergey Mironov *, Rustam Kaibyshev \\ Laboratory of Mechanical Properties of Nanoscale Materials and Superalloys, Belgorod National Research University, Pobeda 85, Belgorod 308015, Russia
}

\section{A R T I C L E I N F O}

\section{Keywords:}

Aluminum alloys

Friction-stir welding

Weld thermal cycle

Electron backscatter diffraction (EBSD)

Microstructure

Texture

\begin{abstract}
A B S T R A C T
In this work, the relationship between the thermal cycle generated during friction-stir welding (FSW) of a 6061 aluminum alloy and the resulting grain structure was studied. To this end, FSW was conducted at measured welding temperatures from 340 to $450{ }^{\circ} \mathrm{C}$ and cooling rates from 15 to $70{ }^{\circ} \mathrm{C} / \mathrm{s}$, and the evolved microstructures were systematically examined using electron backscatter diffraction (EBSD). In all cases, the evolution of the grain structure was governed by continuous recrystallization. At elevated temperatures, however, a competitive recovery retarded the recrystallization kinetics.
\end{abstract}

\section{Introduction}

Friction-stir welding (FSW) is a mature solid-state joining method, that is often considered a revolutionary welding technique because of its energy efficiency, environmental friendliness and high-quality joints [1-3]. As the welded material experiences no melting but instead undergoes a very large strain at elevated temperature, FSW can be considered as a thermomechanical process. If so, the final weld microstructure should be a function of temperature, strain, and strain rate.

Due to the specific character of FSW, the imposed strain, as well as the strain rate, is difficult (or even impossible) to measure experimentally. Hence, these variables are typically determined from appropriate numerical simulations. Depending on the particular welding conditions (as well as on the employed numerical approach), the reported true FSW strain and strain rate ranged from 5 to 190 [4-9] and from $10^{0}$ to $10^{3} \mathrm{~s}^{-1}$ [6,9-12], respectively, thus being very high.

In this context, it is worth noting that the microstructure evolution at very large strains tends to saturate. This effect was discovered during an investigation of severe plastic deformation. Specifically, it has been shown that, after exceeding a threshold strain, the deformation-induced microstructure achieves a quasi-steady state and experiences almost no further significant changes [e.g., 13,14]. This phenomenon is sometimes ascribed to a dynamic balance between the generation and annihilation of dislocations [e.g.,15,16]. As the FSW strain is normally large, it is reasonable to assume that the strain-induced microstructural changes also typically reach the stabilization stage. Hence, a variation in the imposed strain depending on the particular FSW regime should not exert a significant influence on the final microstructure.

The above concept is also applicable to the effect of the strain rate. As is well established in superplasticity studies, there is a certain range of strain rates within which material behavior changes drastically. However, beyond a critical limit, the material flow becomes almost insensitive to the strain rate. This effect is known as a sigmoidal relationship between the strain rate and stress [e.g.,17]. As the strain rate during FSW is typically high, its variation with welding conditions have provide no significant impact on the microstructure.

On the other hand, the welding temperature is well established to exert a critical influence on various aspects of the weld structure, including second-phase particles [e.g.,1,2], grain structure [e.g. 18], and even recrystallization mechanisms [19,20]. For instance, a reduction in FSW temperature to $\sim 0.5 \mathrm{~T}_{\mathrm{m}}$ (where $\mathrm{T}_{\mathrm{m}}$ is the melting point) has been recently shown to suppress dynamic recrystallization and thus may result in the formation of an atypical coarse-grained structure in the stir zone [21]. This unusual effect has been attributed to a specific combination of welding conditions, including low heat input but extremely high strain and strain rate [21].

Considering the high-temperature nature of FSW, it is widely accepted that welded materials may experience additional microstructural changes during cooling to ambient temperature after FSW. This effect is obviously of critical importance for materials experiencing allotropic phase transformations, e.g., for steels. In single-phase alloys, however, the cooling stage may also result in essential changes in the

\footnotetext{
* Corresponding author.

E-mail address: mironov@bsu.edu.ru (S. Mironov).
} 
Table 1

Measured chemical composition of the program material (wt $\%$ ).

\begin{tabular}{llllllll}
\hline $\mathrm{Mg}$ & $\mathrm{Si}$ & $\mathrm{Fe}$ & $\mathrm{Cu}$ & $\mathrm{Mn}$ & $\mathrm{Cr}$ & $\mathrm{Zn}$ & $\mathrm{Al}$ \\
\hline 0.88 & 0.66 & 0.72 & 0.26 & 0.12 & 0.12 & 0.09 & Balance \\
\hline
\end{tabular}

Table 2

Designation of welds.

\begin{tabular}{llll}
\hline $\begin{array}{l}\text { Tool rotation } \\
\text { rate, rpm }\end{array}$ & \multicolumn{4}{l}{ Welding speed, $\mathrm{mm} / \mathrm{min}$} \\
\cline { 2 - 4 } & 125 & 380 & 760 \\
\hline 500 & $500-125$ & $500-380$ & - \\
750 & $750-125$ & $750-380$ & $750-760$ \\
1100 & $1100-125$ & $1100-380$ & $1100-760$ \\
\hline
\end{tabular}

grain structure [e.g.,22-25] or even promote static recrystallization [e. g.,20], thus playing a role in microstructural evolution.

From the above considerations, it seems that the welding temperature and the cooling rate are the key issues that dictate the relationship between FSW conditions and the weld microstructure. Although this concept is not new, quantitative examinations of the relationship between the weld thermal cycle and the FSW-induced microstructure are scant in the scientific literature.

The purpose of the present study was to systematically examine the relationship between the FSW-induced thermal cycle and the final grain structure in the stir zone. To this end, FSW was performed over a wide range of welding temperatures and cooling rates, and the produced microstructures, textures, and misorientation distributions were systematically examined using electron backscatter diffraction (EBSD).

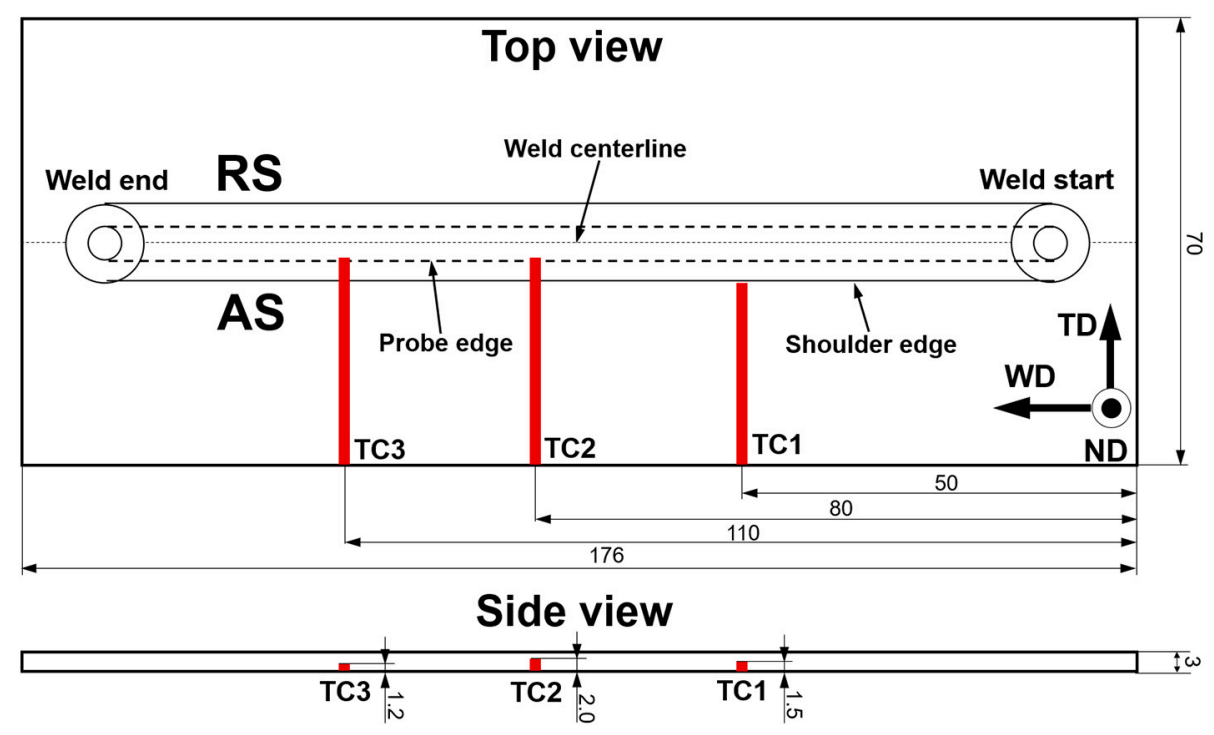

Fig. 1. Thermocouple layout inside the workpieces (unit: $\mathrm{mm}$ ). T1, T2, and $\mathrm{T} 3$ show thermocouples used to measure temperature in the heat-affected zone, the upper section of the stir zone, and the bottom section of the stir zone, respectively. WD, ND, and TD refer to the welding direction, normal direction, and transverse direction, respectively. AS and RS denote the advancing side and the retreating side, respectively. Note that the figure is not to scale.

Table 3

Statistics of the EBSD measurements.

\begin{tabular}{|c|c|c|c|c|c|c|}
\hline \multirow[t]{2}{*}{ Material condition } & \multirow[t]{2}{*}{ Location } & \multirow[t]{2}{*}{ Scan step size, $\mu \mathrm{m}$} & \multirow[t]{2}{*}{ Area of map, $\mu \mathrm{m}^{2}$} & \multirow[t]{2}{*}{ Average confidence index } & \multicolumn{2}{|l|}{ Number } \\
\hline & & & & & Pixels & Grains \\
\hline \multirow[t]{2}{*}{ Base material } & - & 10 & $1370 \times 2950$ & 0.31 & 46,888 & 1169 \\
\hline & & 4 & $468 \times 856$ & 0.52 & 29,140 & 303 \\
\hline 500-125 & Stir zone nugget & 0.5 & $400 \times 312$ & 0.53 & 576,663 & 6800 \\
\hline \multirow[t]{3}{*}{$500-380$} & TMAZ & 0.25 & $350 \times 175$ & 0.13 & $1,133,005$ & 8097 \\
\hline & & 0.5 & $850 \times 225$ & 0.23 & 884,260 & 1996 \\
\hline & Stir zone top & 0.5 & $300 \times 300$ & 0.15 & 416,147 & 17,284 \\
\hline $750-125$ & Stir zone nugget & 1 & $1400 \times 1500$ & 0.23 & $2,427,067$ & 38,211 \\
\hline \multirow{2}{*}{$750-380$} & Stir zone top & 1.3 & $400 \times 400$ & 0.16 & 105,903 & 4691 \\
\hline & Stir zone nugget & 0.7 & $400 \times 400$ & 0.16 & 377,190 & 15,201 \\
\hline \multirow[t]{2}{*}{$750-760$} & Stir zone top & 0.5 & $400 \times 436$ & 0.09 & 806,696 & 15,892 \\
\hline & Stir zone nugget & 0.5 & $500 \times 525$ & 0.20 & $1,213,607$ & 37,842 \\
\hline \multirow[t]{2}{*}{$1100-125$} & TMAZ & 2 & $1000 \times 1000$ & 0.37 & 289,289 & 1648 \\
\hline & & 1 & $1200 \times 1000$ & 0.29 & $1,386,578$ & 9972 \\
\hline
\end{tabular}

Note: TMAZ is thermo-mechanically affected zone. 

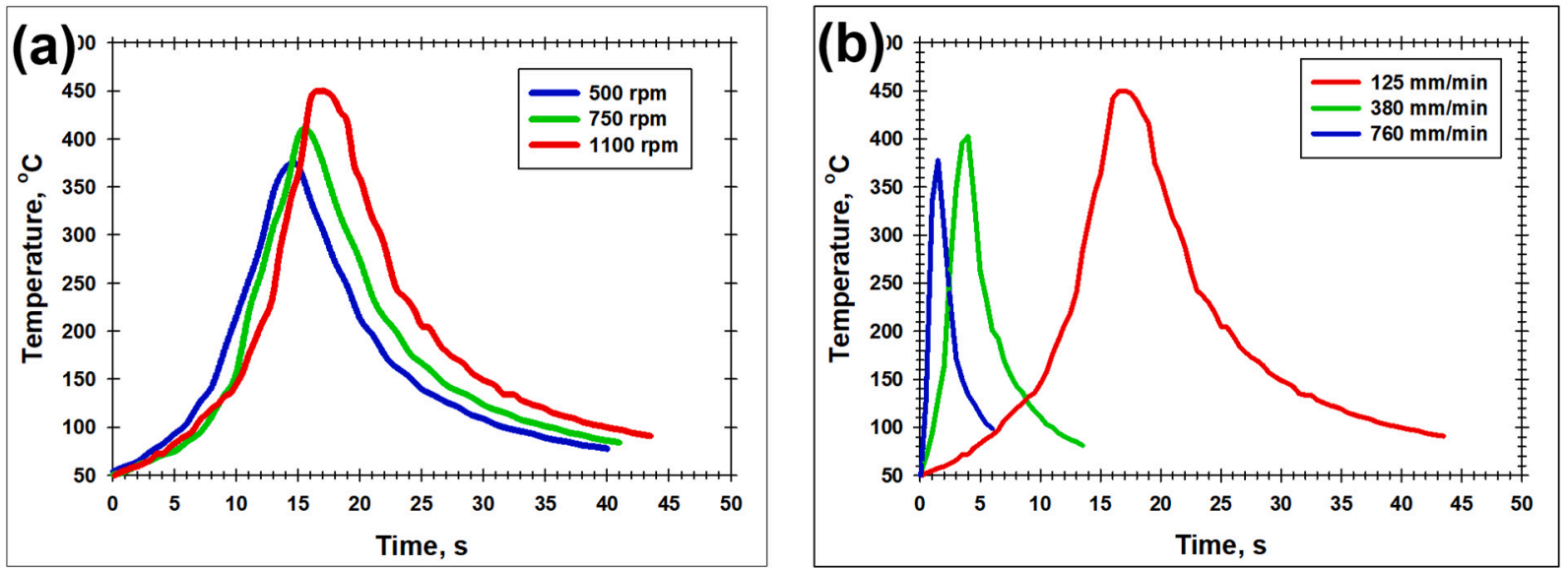

Fig. 2. Typical measured thermal cycles as a function of (a) tool rotation rate and (b) welding speed. In both cases, the temperature data were taken from the weld nugget. In (a), the thermal cycles were recorded at the welding speed of $125 \mathrm{~mm} / \mathrm{min}$. In (b), the temperatures were measured at the tool rotation rate of $1100 \mathrm{rpm}$.
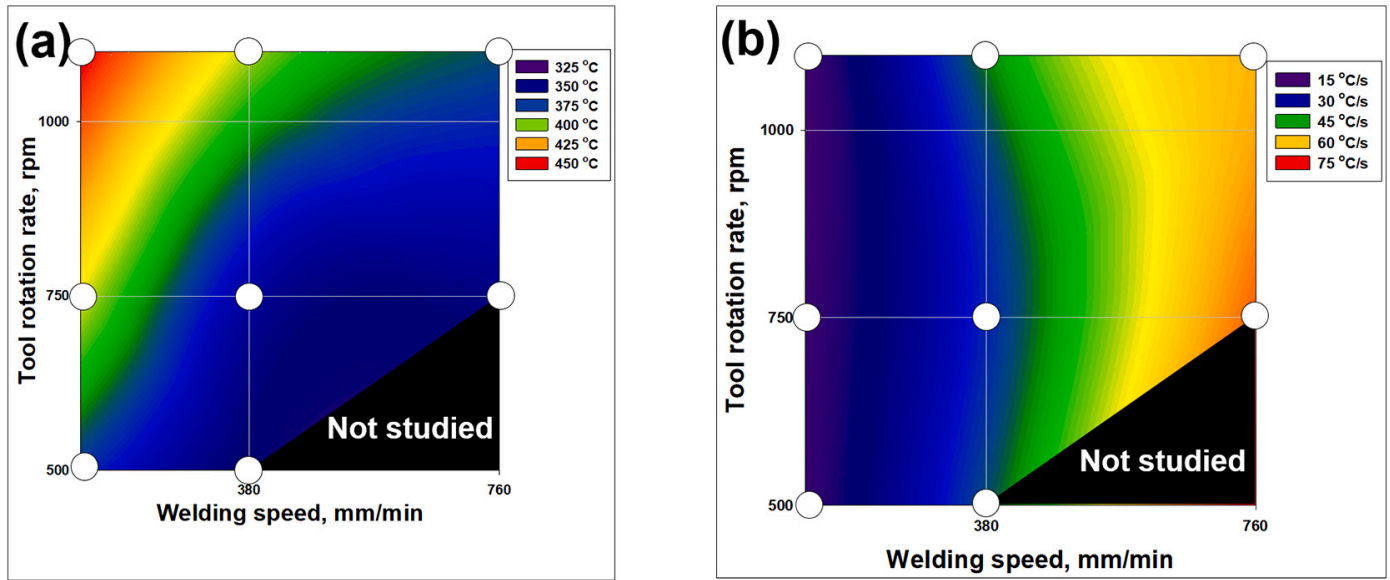

Fig. 3. The combined influence of FSW variables on (a) the peak welding temperature and (b) the average cooling rate measured in the upper section of the stir zone. In (a) and (b), the circles show the FSW conditions at which the measurements were actually made.

\section{Experimental}

The program material used in the present study was a commercial 6061 aluminum alloy whose measured chemical composition is shown in Table 1. This material is characterized by a relatively wide FSW processing window, and therefore, it was decided to be particularly convenient for the purpose of this work. The thermomechanical history of the material has been described elsewhere [26]. Briefly, a cast ingot was consistently homogenized, hot extruded, and then subjected to the standard T6 tempering treatment, i.e., solutionized at $540{ }^{\circ} \mathrm{C}$ for $1 \mathrm{~h}$, water quenched and artificially aged at $160{ }^{\circ} \mathrm{C}$ for $8 \mathrm{~h}$. The produced material was characterized by a millimeter-scale elongated grain structure (supplementary Figs. S1a and b) and a relatively strong fiber texture consisting of $\{h k l\}\langle 111\rangle$ and $\{h k l\}\langle 100\rangle$ components (supplementary Fig. S1c). This material condition was denoted as the base material.

3-mm-thick sheets of the base material were friction-stir butt welded under the plunge-depth control mode. The details of the welding process were provided in a previous work [26]. Briefly, the welding tool consisted of a concave-shaped shoulder with a diameter of $12.5 \mathrm{~mm}$ and an M5 cylindrical probe with a length of $2.7 \mathrm{~mm}$. To provide diversity in the welding conditions, the key FSW variables (i.e., the tool rotation rate and the welding speed) were systematically altered over a wide range, as shown in Table 2. To differentiate the welds throughout this manuscript, the $\mathrm{N} \times \mathrm{V}$ code was employed, where $\mathrm{N}$ is the tool rotation rate (rpm) and $\mathrm{V}$ is the welding speed $(\mathrm{mm} / \mathrm{min})$, as indicated in Table 2 . The typical convention for FSW geometry was adopted, where WD is the welding direction, TD is the transverse direction, and ND is the normal direction of the welded sheets.

The weld thermal cycle was measured in the stir zone and the heataffected zone. A schematic layout of the thermocouples is shown in Fig. 1. Within the stir zone, the temperature was recorded at two locations: the upper section and the weld nugget. To avoid damage to the thermocouples by the rotating tool, measurements were made outside the stir zone (Fig. 1). Therefore, the recorded temperatures were likely somewhat lower than the actual temperatures.

Microstructural observations were conducted on transverse crosssections (TD $\times$ ND plane) of the produced welds and were performed primarily by EBSD. The microstructural specimens for EBSD were prepared using conventional metallographic techniques with the final step comprised of electropolishing in a solution of 25 pct. Nitric acid in methanol.

EBSD was performed using FEI Quanta 600 and FEI Nova NanoSEM 450 scanning electron microscopes both equipped with a TSL OIM ${ }^{\mathrm{TM}}$ system and operated at an accelerating voltage of $30 \mathrm{kV}$. The statistical details of EBSD mapping are shown in Table 3. To minimize the possibility of misindexing error, seven Kikuchi bands were analyzed for each diffraction pattern. To improve the fidelity of the EBSD data, they were automatically cleaned using the standard grain-dilation option in the EBSD software. During this procedure, the fine grains comprising three 
Table 4

Effect of FSW conditions on the weld thermal cycle.

\begin{tabular}{|c|c|c|c|c|c|}
\hline \multirow[t]{3}{*}{ Welds } & \multirow{3}{*}{$\begin{array}{l}\text { Heat-affected zone } \\
\text { Peak temperature, }{ }^{\circ} \mathrm{C}\end{array}$} & \multicolumn{4}{|l|}{ Stir zone } \\
\hline & & \multicolumn{2}{|l|}{ Upper section } & \multicolumn{2}{|l|}{ Weld nugget } \\
\hline & & Peak temperature, ${ }^{\circ} \mathrm{C}$ & $\begin{array}{l}\text { Average cooling } \\
\text { rate, }{ }^{\circ} \mathrm{C} / \mathrm{s}\end{array}$ & Peak temperature, ${ }^{\circ} \mathrm{C}$ & $\begin{array}{l}\text { Average cooling } \\
\text { rate, }{ }^{\circ} \mathrm{C} / \mathrm{s}\end{array}$ \\
\hline $500-125$ & 247 & 385 & 16.6 & 372 & 16.8 \\
\hline $500-380$ & 226 & 369 & 38.7 & 342 & 40.4 \\
\hline $750-125$ & 247 & 411 & 16.2 & 406 & 16.1 \\
\hline $750-380$ & 244 & 373 & 41.6 & 358 & 36.8 \\
\hline $750-760$ & 233 & 384 & 57.2 & 350 & 67.7 \\
\hline $1100-125$ & 312 & 444 & 15.7 & 450 & 15.2 \\
\hline $1100-380$ & 252 & 405 & 40.7 & 403 & 43.2 \\
\hline $1100-760$ & 248 & & & 378 & 62.0 \\
\hline
\end{tabular}

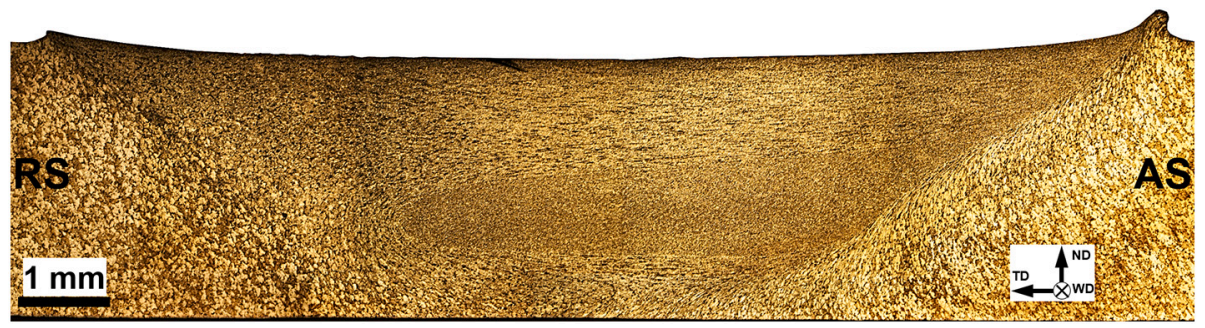

Fig. 4. Typical optical image of the weld cross-section. RS and AS denote the retreating side and advancing side, respectively. Note: The image of the $1100-125$ weld is shown.
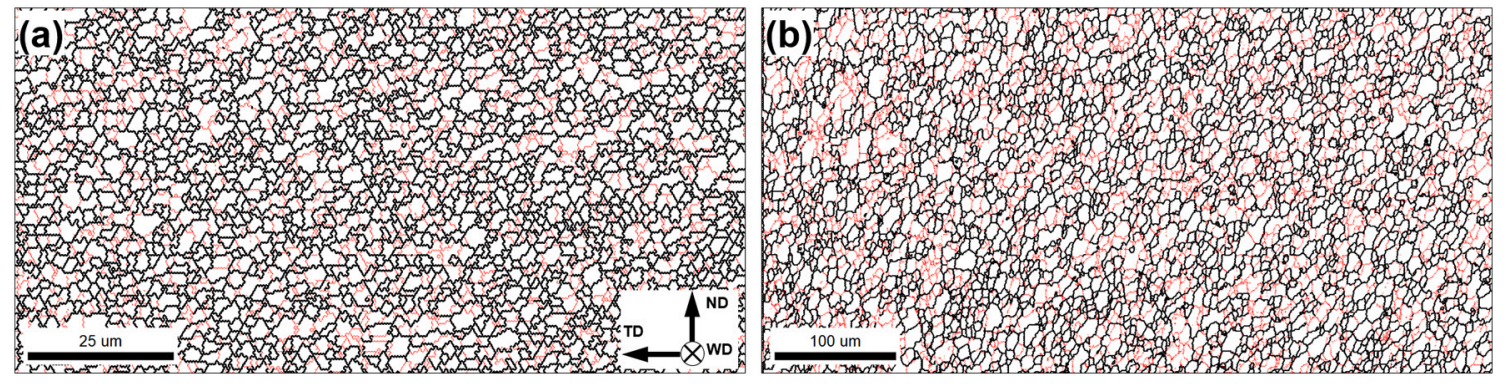

Fig. 5. Selected portions of EBSD grain-boundary maps illustrating typical microstructures evolved in the stir zone of (a) low- and (b) high-temperature welds. The red and black lines depict LABs and HABs, respectively. Note the difference in scales. In (a) and (b), the maps were taken from the upper sections of the 500-380 weld and 1100-125 weld, respectively.

or fewer pixels were removed from EBSD maps. Due to the limited angular accuracy of EBSD, a lower-limit misorientation cutoff of $2^{\circ}$ was applied. To differentiate low-angle boundaries (LABs) from high-angle boundaries (HABs), a $15^{\circ}$ criterion was employed. The grain size was measured by using the grain reconstruction approach [27].

\section{Results}

\subsection{Temperature measurements}

The typical effect of FSW conditions on the weld thermal cycle is shown in Fig. 2; the entire set of temperature data is provided in supplementary Figs. S2 to S4. The peak welding temperatures and the average cooling rates ${ }^{1}$ as a function of the tool rotation rate and the welding speed are given in Fig. 3, Table 4, and supplementary Fig. S5.

As expected, the peak temperature increased with increasing tool

\footnotetext{
${ }^{1}$ Assuming a substantial deceleration of diffusion-driven processes below $\sim 100{ }^{\circ} \mathrm{C}$, the average cooling rate in Fig. $3 \mathrm{~b}$ and Table 4 was quantified as $C=$ $(T-100) / \tau$, where $T$ is the peak measured temperature $\left({ }^{\circ} \mathrm{C}\right)$ and $\tau$ is the time required to cool to $100{ }^{\circ} \mathrm{C}(\mathrm{s})$.
}

rotation rate but decreased with welding speed (Figs. 2 and 3a). Depending on the combination of the welding variables, the measured stir-zone temperature varied from $\sim 340$ to $450{ }^{\circ} \mathrm{C}$ (Table 4), i.e., from $0.72 \mathrm{~T}_{\mathrm{m}}$ to $0.85 \mathrm{~T}_{\mathrm{m}}$, respectively (where $\mathrm{T}_{\mathrm{m}}$ is the melting point). In contrast, the cooling rate was found to be primarily governed by the welding speed (Fig. 3b), ranging from 15 to $70{ }^{\circ} \mathrm{C} / \mathrm{s}$ (Table 4). Remarkably, even the highest cooling rate was well below $\sim 700{ }^{\circ} \mathrm{C} / \mathrm{s}$ expected for water quenching. This implied the possibility of microstructural changes occurring during the weld cooling cycle, as mentioned in Section 1.

\subsection{Structural morphology and grain size}

A typical low-magnification optical image of the weld cross-section is shown in Fig. 4; the entire set of weld cross-section micrographs is shown in supplementary Fig. S6. In all cases, a clear stir zone was observed. Within the stir zone, two distinct microstructural regions could be seen: a basin-like upper section and an elliptical-shaped nugget zone (Fig. 4). These two areas are normally found in friction-stirred materials and are conventionally attributed to the influence of the tool shoulder and the tool probe on material flow. Subtle weld thinning in the 

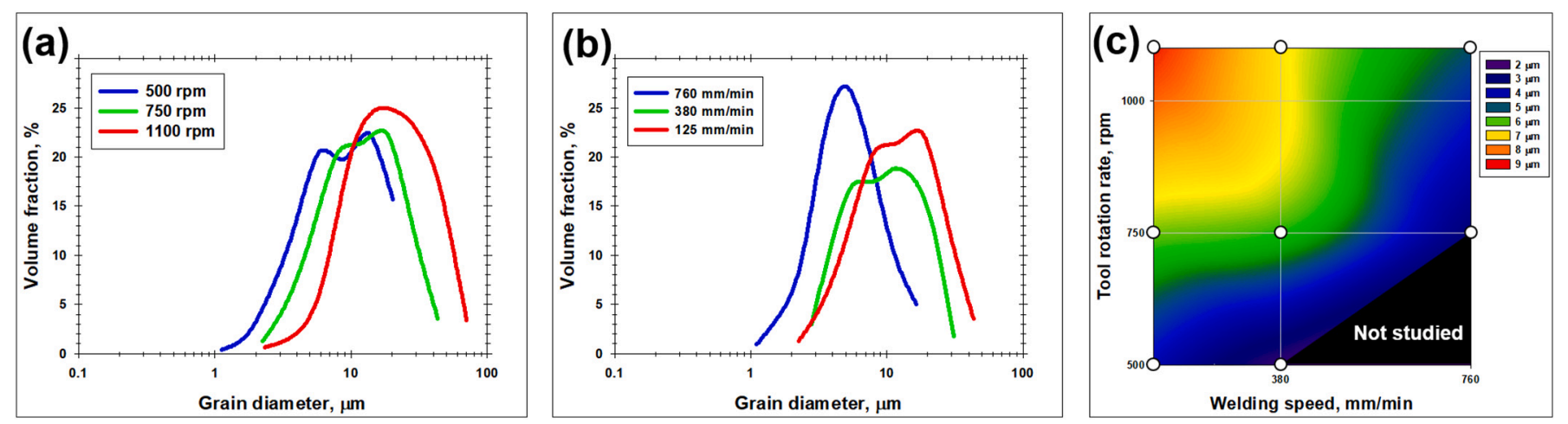

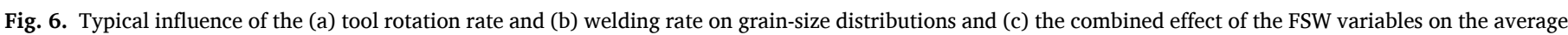

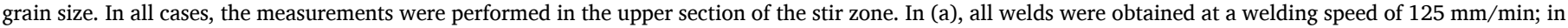

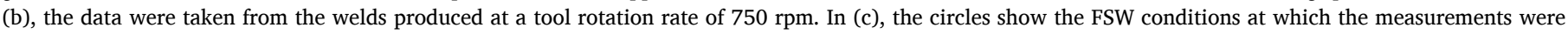
actually made.

Table 5

Microstructural characteristics of the stir-zone material in various welds.

\begin{tabular}{|c|c|c|c|c|c|c|}
\hline \multirow[t]{2}{*}{ Weld } & \multicolumn{2}{|c|}{ Mean grain size, $\mu \mathrm{m}$} & \multicolumn{2}{|c|}{$\begin{array}{l}\text { Texture strength*, times } \\
\text { random }\end{array}$} & \multicolumn{2}{|c|}{$\begin{array}{l}\text { HAB fraction, } \\
\%\end{array}$} \\
\hline & Top & Nugget & Top & Nugget & Top & Nugget \\
\hline $500-125$ & $4.1 \pm 1.6$ & $3.9 \pm 1.6$ & 8.6 & 6.6 & 67 & 71 \\
\hline $500-380$ & $2.3 \pm 0.7$ & $2.5 \pm 0.6$ & 6.8 & 4.6 & 74 & 81 \\
\hline $750-125$ & $6.6 \pm 2.7$ & $5.6 \pm 2.2$ & 7.9 & 8.4 & 62 & 62 \\
\hline $750-380$ & $5.8 \pm 1.7$ & $3.3 \pm 0.9$ & 9.1 & 3.8 & 68 & 77 \\
\hline $750-760$ & $3.2 \pm 1.0$ & $2.6 \pm 0.8$ & 4.7 & 3.8 & 66 & 73 \\
\hline 1100-125 & $8.7 \pm 3.6$ & $8.5 \pm 3.0$ & 7.5 & 5.2 & 65 & 68 \\
\hline $1100-380$ & $6.8 \pm 2.3$ & $6.3 \pm 1.9$ & 5.1 & 5.0 & 66 & 71 \\
\hline $1100-760$ & $5.7 \pm 2.3$ & $5.0 \pm 1.6$ & 8.1 & 3.8 & 64 & 72 \\
\hline
\end{tabular}

Note: Error shows standard deviation.

* Texture strength was measured as the peak intensity in 111 pole figure.

upper section of the stir zone is also worth noting (Fig. 4 and supplementary Fig. S6). As emphasized by Meng et al. [3], this inherent characteristic of the FSW process may essentially deteriorate the mechanical performance of the produced welds.

To attain in-depth insight into the evolved grain structure, EBSD maps were taken from both microstructural regions of each weld. Representative EBSD grain-boundary maps are shown in Fig. 5; the entire set of acquired EBSD maps is given in supplementary Figs. S7 and S8. In all cases, FSW resulted in substantial grain refinement. The stirzone microstructures consisted of relatively fine grains that contained developed LAB substructures. These microstructures are typically observed in friction-stirred aluminum alloys and are generally attributed to a continuous recrystallization process [e.g.,18,22,24,28].

The grain size statistics derived from the EBSD maps are summarized in Fig. 6, Table 5, and supplementary Figs. S9 to S11a. As expected, the grain size coarsened with increasing tool rotation rate (Fig. 6a) but refined with increasing welding speed (Fig. 6b). Hence, the relationship between the FSW conditions and the mean grain size was qualitatively similar to that of the measured welding temperature (compare Figs. $6 \mathrm{c}$ and 3a). Moreover, the microstructure in the upper section of the stir zone was typically slightly coarser than that in the weld nugget (Table 5). Depending on the particular combination of welding variables (as well as on the particular location within the stir zone), the mean grain size varied from 2.3 to $8.7 \mu \mathrm{m}$ (Table 5).

\subsection{Texture}

To examine the possible influence of FSW conditions on the stir-zone texture, orientation data were derived from the EBSD maps and arranged as 111 and 110 pole figs. A typical example is shown in Fig. 7, while the entire dataset is provided in supplementary Figs. S12 and S13. It is important to note that the pole figures were appropriately rotated to align their reference frames with the presumed geometry of simple-shear deformation induced during FSW (as discussed by Fonda et al. [29]). The effects of the welding variables on the texture strength and volume fraction of textural components are summarized in Tables 5 and 6, respectively.

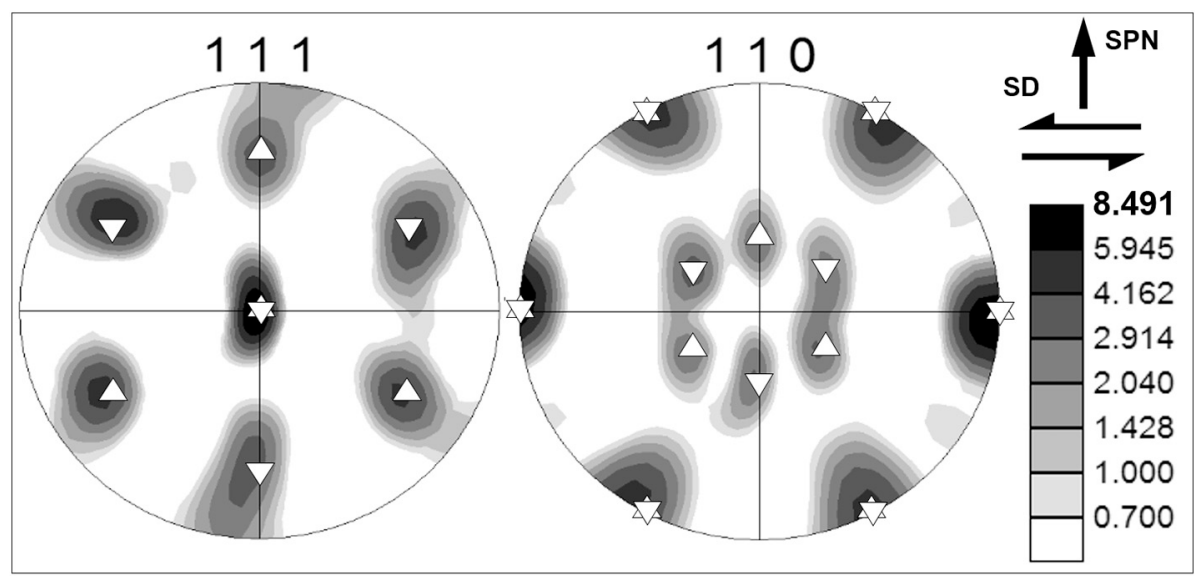

$B\{1 \overline{1} 2\}<110>\quad \nabla B\{\overline{11} \overline{2}\}<\overline{110}>$
Fig. 7. $\{111\}$ and $\{110\}$ pole figures illustrating the typical texture found in the stir zone. SD and SPN define the shear direction and the shear plane normal, respectively. The texture shown was measured in the upper section of the stir zone of the 500-125 weld. For simplicity, the positions of the ideal $\mathrm{B} /-\mathrm{B}\{112\}\langle 110\rangle$ orientations are indicated in the pole figures. Note: The experimental pole figures were appropriately rotated to align them with the presumed geometry of simple shear. 
Table 6

Effect of FSW conditions on the volume fraction of textural components that evolved in the stir zone.

\begin{tabular}{|c|c|c|c|c|c|c|}
\hline \multirow[t]{2}{*}{ Weld condition } & \multicolumn{2}{|c|}{$h k l$}$\langle 110\rangle$ & $\multicolumn{2}{|c|}{111}<u v w>$ & \multicolumn{2}{|c|}{$\mathrm{B} /-\mathrm{B}\{112\}<110>$} \\
\hline & Top & Nugget & Top & Nugget & Top & Nugget \\
\hline $500-125$ & 55.1 & 53.1 & 31.4 & 24.8 & 17.8 & 13.3 \\
\hline $500-380$ & 53.8 & 30.1 & 26.6 & 25.6 & 16.3 & 5.3 \\
\hline $750-125$ & 52.3 & 50.3 & 30.7 & 36.6 & 15.6 & 14.0 \\
\hline $750-380$ & 63.3 & 39.4 & 26.4 & 17.7 & 24.3 & 9.9 \\
\hline $750-760$ & 46.1 & 37.1 & 17.9 & 20.4 & 13.2 & 10.7 \\
\hline $1100-125$ & 54.6 & 50.6 & 29.1 & 16.1 & 14.1 & 13.3 \\
\hline $1100-380$ & 45.4 & 43.3 & 21.6 & 14.6 & 12.9 & 13.6 \\
\hline $1100-760$ & 53.2 & 36.5 & 32.8 & 20.7 & 18.9 & 14.6 \\
\hline
\end{tabular}

In all cases, the stir zone texture could be described in terms of a superposition of the $B / \bar{B}\{112\}<110>$ simple-shear component and $\{h k l\}<110>$ and $\{111\}<u v w>$ partial fiber orientations (Fig. 6 and Table 6). The development of a $B / \bar{B}$ texture is often reported for frictionstirred aluminum alloys [e.g., 18,22,24,27].

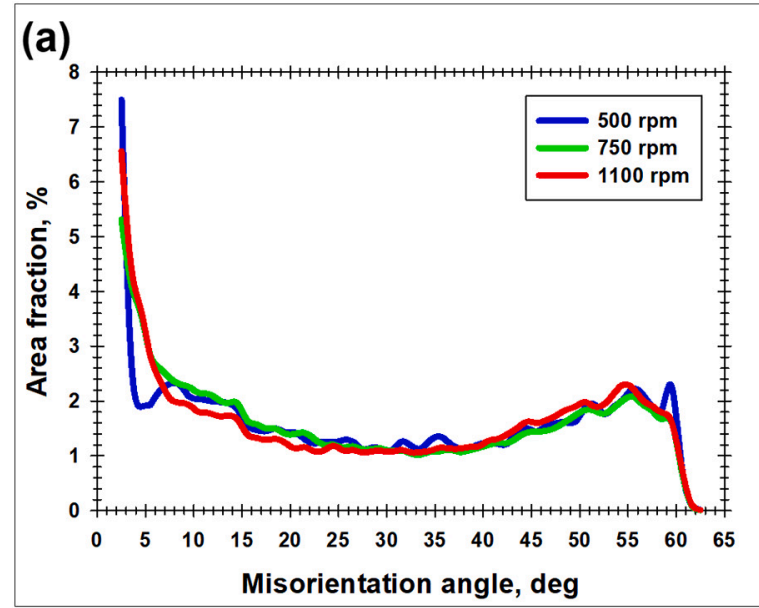

\subsection{Misorientation distribution}

The typical effect of the welding variables on the misorientationangle distribution is shown in Fig. 8a; the entire set of misorientationangle data is given in supplementary Figs. S14 and S15. In all cases, the distributions were qualitatively similar to each other and were characterized by a sharp low-angle peak and a broad maximum near $60^{\circ}$.

The fraction of LABs was found to be sensitive to the FSW parameters (Fig. 8b and supplementary Fig. S11b). Specifically, the largest LAB proportion was observed at the lowest welding speed and the highest tool rotation rate (Fig. $8 b$ ).

While LABs are normally observed in friction-stir welded aluminum alloys, the origin of the $60^{\circ}$ peak in the misorientation-angle distributions is less evident. To assist in the interpretation of this result, the socalled uncorrelated (or texture-derived) misorientation distributions were calculated. To this end, 1000 pixels were arbitrarily selected from an EBSD map, and all possible misorientations between them were calculated using a standard option in the EBSD software. A typical comparison of the measured and texture-derived distributions is shown in Fig. 9a. From the figure, it appears that the broad maximum at $60^{\circ}$ was likely associated with a specific texture that evolved in the friction-

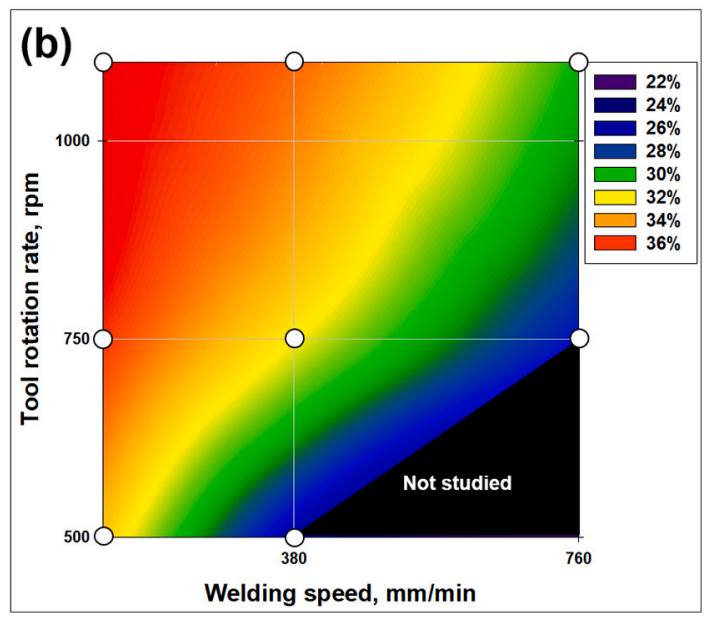

Fig. 8. The typical effect of welding variables on the (a) misorientation-angle distribution and (b) LAB fraction. In all cases, the measurements were performed in the upper section of the stir zone. In (a), the welds were produced at a welding speed of $125 \mathrm{~mm} / \mathrm{min}$. In (b), the circles show the welding conditions at which the measurements were actually made.

(a)

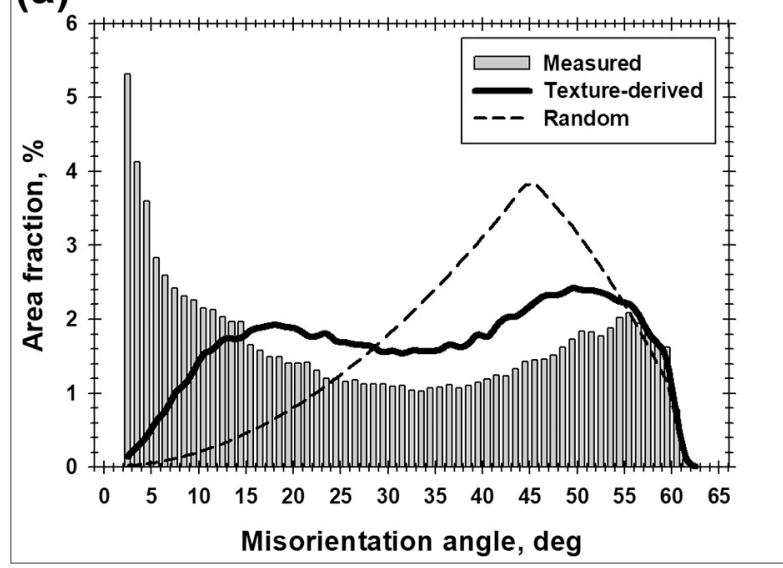

(b)

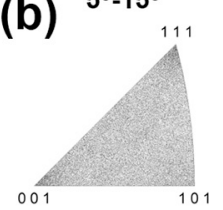

$15^{\circ}-25^{\circ}$

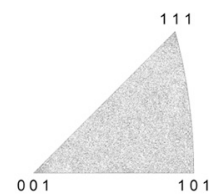

$35^{\circ}-45^{\circ}$

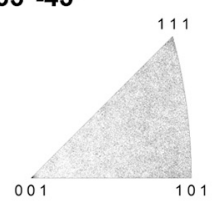

$45^{\circ}-55^{\circ}$

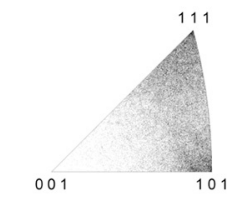

$25^{\circ}-35^{\circ}$

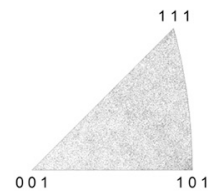

$55^{\circ}-62.8^{\circ}$

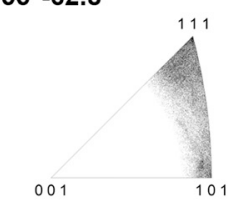

Fig. 9. (a) Comparison of the experimental misorientation-angle distribution with the texture-derived one and (b) a typical misorientation-axis distribution. In both cases, the data were taken from the upper section of the stir zone of the 750-125 weld. See Section 3.4 for details. 

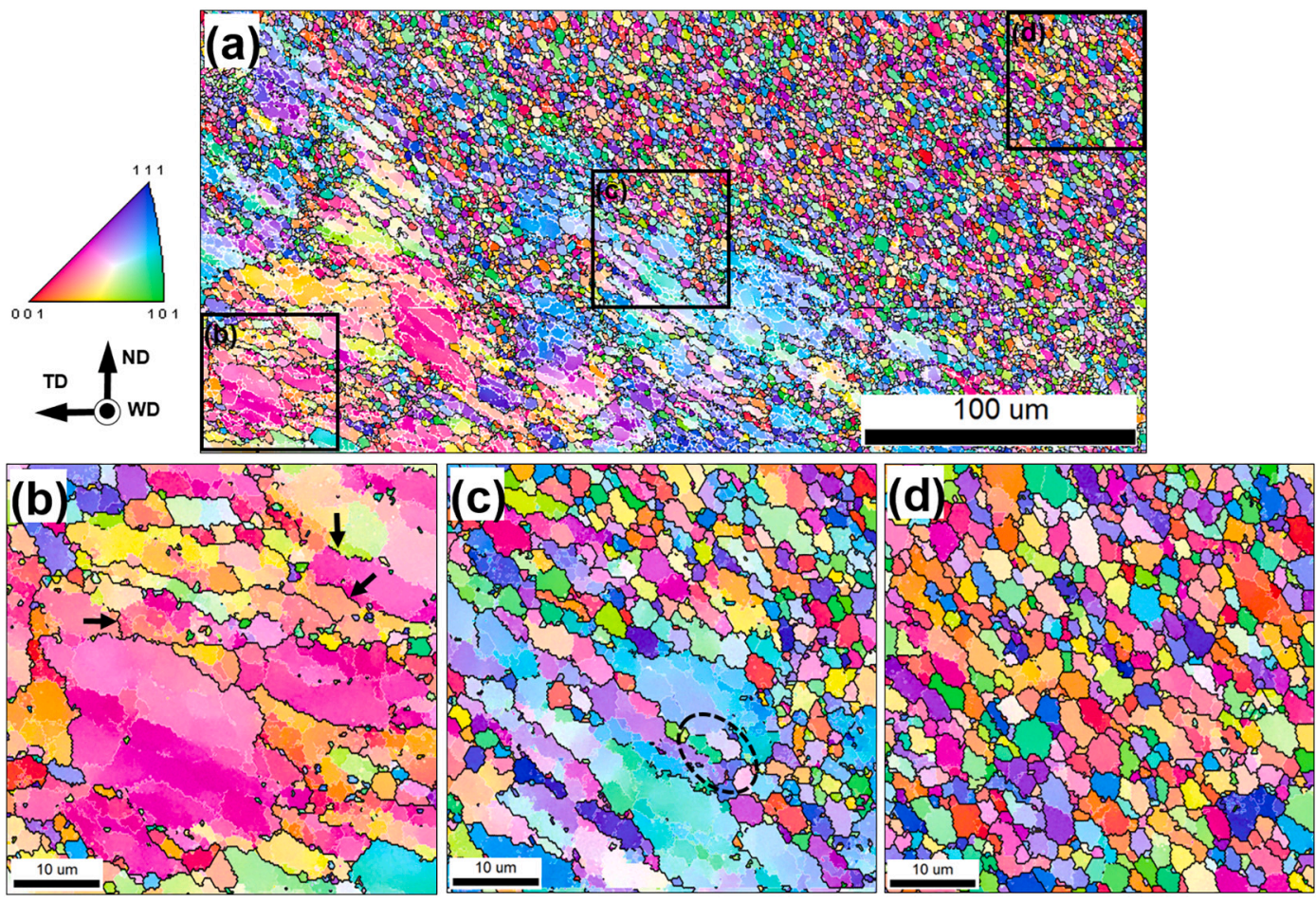

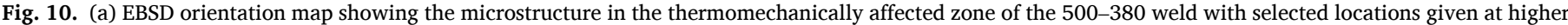

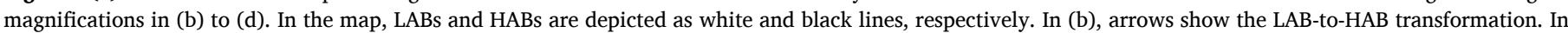
(c), the selected area exemplifies the subgrain-to-grain transition.

stirred material.

This conclusion can be rationalized on the basis of an analysis of the $B / \bar{B}$ texture components in Fig. 7. Considering the clear hexagonal symmetry in the distribution of the textural peaks in the 111 pole figure, it can be assumed that the misorientation between the $B(1 \overline{1} 2)[110]$ and $\bar{B}(\overline{1} 1 \overline{2})[\overline{11} 0]$ components was close to $60^{\circ}\langle 111\rangle$. Indeed, this suggestion agreed well with the typical misorientation-axis distribution shown in Fig. 9b, in which a pronounced clustering of the rotational axes of $60^{\circ}$ boundaries near the $\langle 111\rangle$ pole was evident.

\subsection{Recrystallization mechanism}

To explore the mechanism(s) controlling the grain structure evolution during FSW, the microstructural changes in the thermomechanically affected zone were analyzed. Across this region, the material transformed from its parent state to the final condition, thus providing insight into the microstructural processes that occurred during welding. To encompass the entire studied temperature range, microstructural data were obtained from the 500-380 and 1100-125 welds, which represent the lowest and highest FSW temperatures, respectively (Table 4). ${ }^{2}$ The acquired EBSD maps are shown in Figs. 10 and 11.

In the low-temperature weld, the microstructural evolution initiated from the extensive development of deformation-induced LABs (Figs. 10a and $b$ ). The misorientation of the LABs rapidly exceeded $15^{\circ}$, thereby transforming them into HABs (arrows in Fig. 10b). Accordingly, the subgrains evolved into grains (an example is circled in Fig. 10c), resulting in the development of a fine-grained structure (Fig. 10d).

At elevated temperatures, the initial stage of microstructural evolution was characterized by essential shearing of the parent grains in a

\footnotetext{
2 The measured temperature in the thermomechanically affected zone of the $500-380$ weld varied from 226 to $369{ }^{\circ} \mathrm{C}$ whereas that of the $1100-125$ weld ranged from 312 to $450{ }^{\circ} \mathrm{C}$ (Table 4 ).
}

flow pattern around the stir zone (Figs. 11a and b). When approaching the stir zone, deformation-induced HABs were observed in the grain interiors (arrows in Fig. 11c). Their development promoted a gradual transformation of subgrains into grains (selected areas in Fig. 11c), which also gave rise to the fine-grained structure (Fig. 11d).

From the above microstructural observations, in both cases, the grain structure development was governed by a gradual LAB-to-HAB transformation, i.e., a phenomenon that virtually fits the definition of continuous recrystallization. This agrees well with previous reports in the literature [e.g. 18,22,24,27].

\subsection{Secondary particles}

It is worth noting that the material examined in the present study is a heat-treatable alloy whose deformation behavior and annealing performance are greatly influenced by secondary particles. The effect of FSW on precipitation phenomena occurring in the studied material has been reported in previous work [26], and therefore such an analysis was beyond the scope of the present work. To provide a broad microstructural pattern, however, the key results are briefly summarized in this section.

In the initial T6-tempered condition, the base material contained a high density of nanoscale $\beta^{/ /}$dispersoids evenly distributed in the grain interior (supplementary Fig. S16a). In the heat-affected zone, no significant changes in the grain structure were found [26]. On the other hand, transmission-electron-microscopy (TEM) observations revealed essential precipitation coarsening (supplementary Figs. S16b and c). As expected, this effect was most pronounced in the high-heat-input welds, in which the longitudinal size of the needle-shaped particles reached $\sim 200 \mathrm{~nm}$ (supplementary Fig. S16c). It is likely, therefore, that the original coherent $\beta^{\prime /}$ phase had transformed into semicoherent $\beta^{\prime}$ phase.

In the stir zone, the particle behavior was found to be principally influenced by the weld thermal cycle. In the low-heat-input welds, the secondary particles experienced spheroidization and further growth (supplementary Fig. S17a) thereby presumably evolving into the stable $\beta$ 

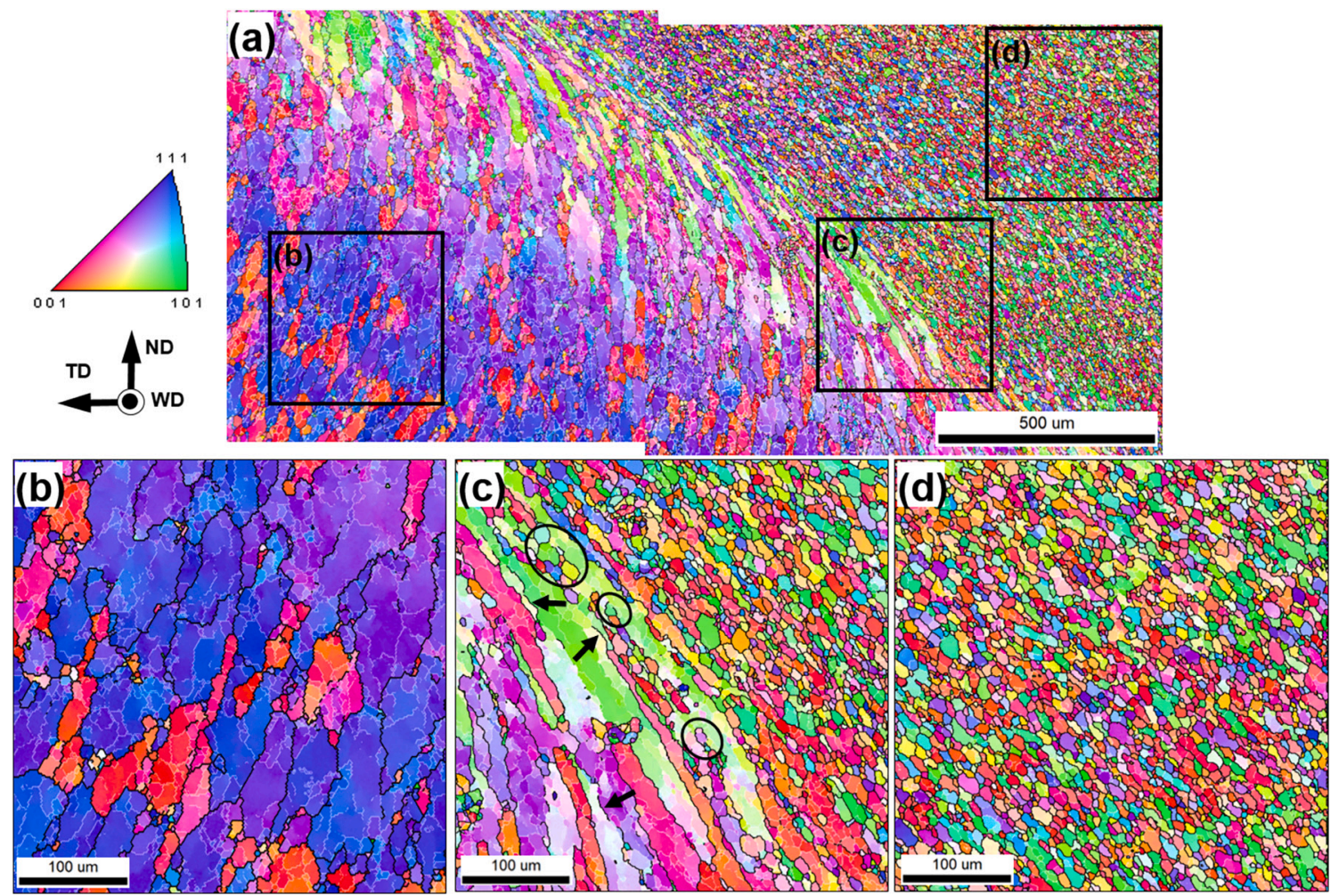

Fig. 11. (a) EBSD orientation map showing the microstructure in the thermomechanically affected zone of the 1100-125 weld (a) with selected locations given at higher magnifications in (b) to (d). In the map, LABs and HABs are depicted as white and black lines, respectively. In (c), arrows show the LAB-to-HAB transformation, and the selected areas exemplify the subgrain-to-grain transition.

phase. In the high-heat-input welds, in contrast, the precipitates had mainly dissolved (supplementary Fig. S17b).

\section{Discussion}

As shown in Section 3, neither microstructural morphology nor texture was greatly influenced by the FSW conditions (Figs. 5 and 7, respectively). The morphological invariance is perhaps attributable to the operation of the same microstructural mechanism (i.e., continuous recrystallization) in the entire studied FSW range. Similarly, the low sensitivity of the texture to the welding variables presumably indicates nearly the same character of material flow.

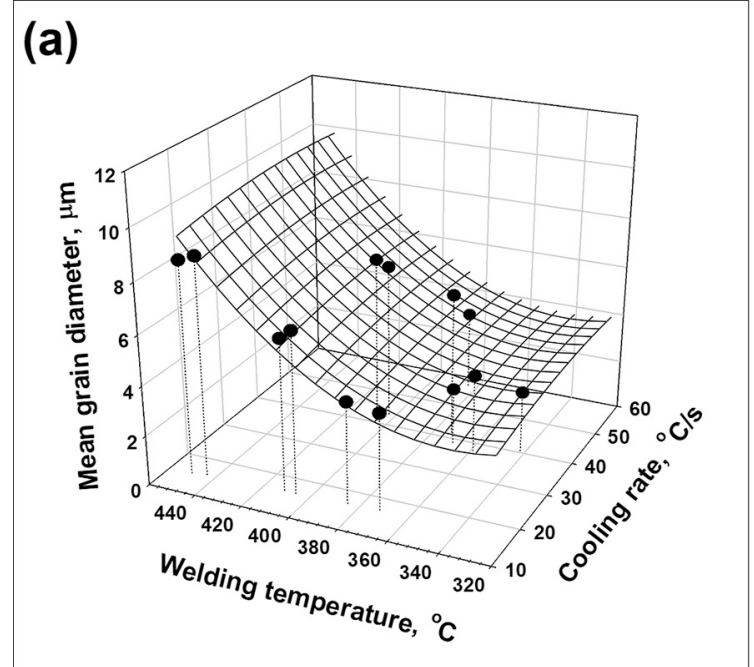

On the other hand, the mean grain size and HAB fraction exhibited an essential sensitivity to the FSW parameters (Figs. 6c and 8b). Assuming no significant influence of the FSW strain and strain rate on the microstructure (as discussed in Section 1), the grain size data and $\mathrm{HAB}$ data were plotted as a function of the welding temperature and cooling rate in Fig. 12.

To obtain the quantitative relationship between the process variables and the microstructural data, the experimental results were fitted with various standard equations available in commercial SigmaPlot 11.0 software. The best fit was obtained when using the paraboloid equation $z=z_{0}+a x+b y+c x^{2}+d y^{2}$; the fitted data are shown in Fig. 12. In this case, the $\mathrm{R}^{2}$ values for the mean grain size and HAB fraction were 0.85

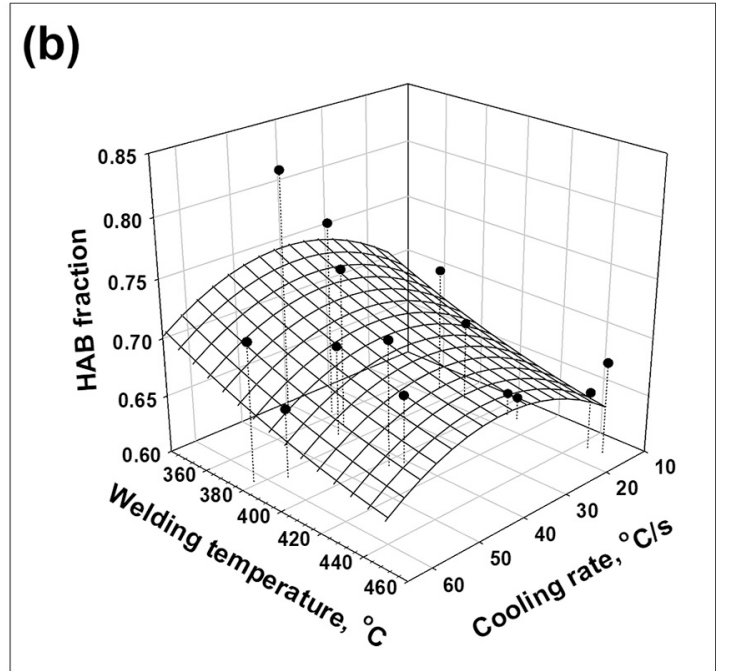

Fig. 12. The combined influence of the peak welding temperature and average cooling rate on the (a) average grain size and (b) HAB fraction. 

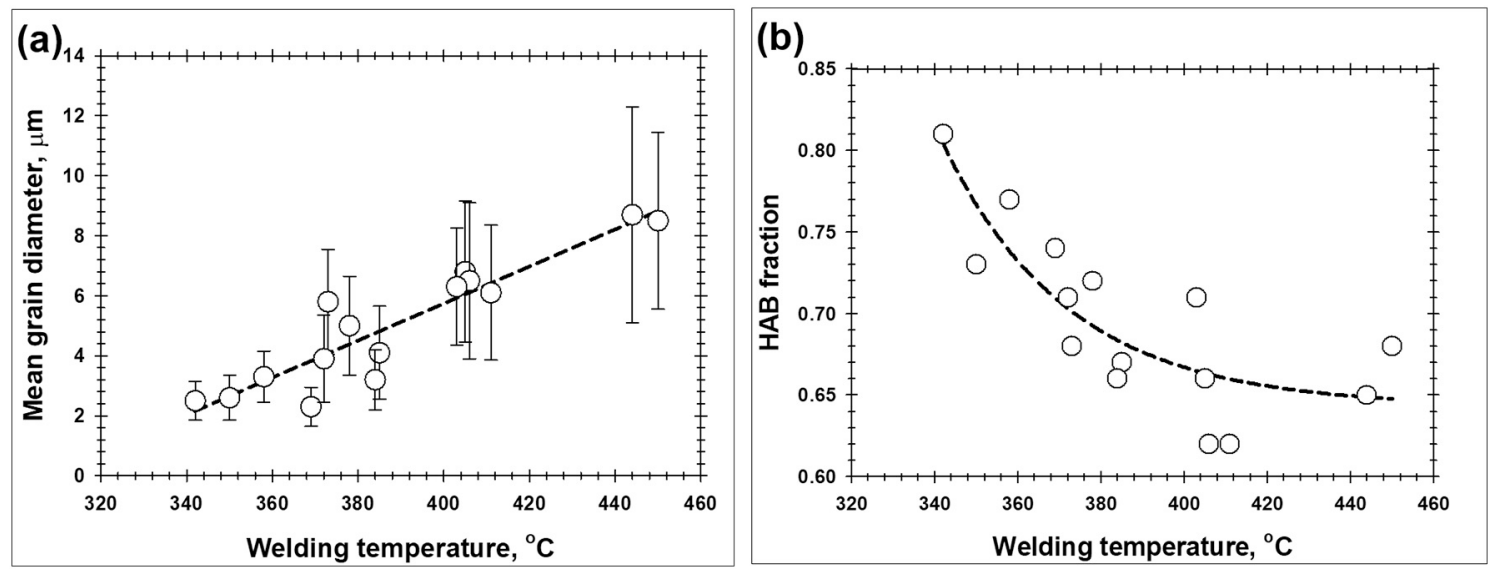

Fig. 13. Effect of the welding temperature on (a) mean grain size and (b) HAB fraction.

and 0.83 , respectively. The relatively high fitting accuracy suggested that the weld thermal cycle was indeed the key factor that governs the weld microstructure, thus supporting the initial idea of this work.

As expected, the mean grain size increased significantly with the welding temperature (Figs. 12a and 13a), in agreement with numerous previous FSW studies [e.g.,1,2]. In contrast, the cooling rate exerted almost no influence on the grain dimension (Fig. 12a). The latter observation presumably indicated that the welded material experienced no substantial microstructural coarsening during the weld cooling cycle.

Surprisingly, the HAB fraction was found to decrease with welding temperature (Figs. 12b and 13b). As proposed in a previous work [18], this effect may be associated with increased recovery activity. At elevated temperatures, recovery should efficiently decrease the dislocation density and thus slow the progressive development of dislocationinduced boundaries, i.e., retards the kinetics of continuous recrystallization. This concept explains the relatively high LAB fraction observed in the high-temperature welds (Fig. 8b).

On the other hand, the HAB fraction exhibited a nonmonotonic dependence on the cooling rate, with a peak magnitude at approximately $40{ }^{\circ} \mathrm{C} / \mathrm{s}$ (Fig. 12b). The origin of this effect is not clear.

\section{Conclusions}

The present work was undertaken to investigate the relationship between the FSW-induced thermal cycle and the weld microstructure. To this end, FSW was conducted at temperatures ranging from 340 to $450{ }^{\circ} \mathrm{C}$ and cooling rates ranging from 15 to $70{ }^{\circ} \mathrm{C} / \mathrm{s}$, and the microstructures, textures, and misorientation distributions that evolved in the stir zone were systematically examined using EBSD. The main conclusions of this work are as follows.

In the entire studied FSW range, microstructural evolution was shown to be governed by continuous recrystallization, and the evolved texture was dominated by the $B / \bar{B}\{112\}<110>$ simple-shear orientation.

An increase in the welding temperature promoted microstructural coarsening but also resulted in retardation of the recrystallization kinetics. The latter effect was attributed to the enhancement of the recovery processes, which reduced the dislocation density and thus obstructed the progressive development of deformation-induced boundaries.

The relatively good fit between the welding temperature and the grain structure produced in the stir zone suggests that the processingmicrostructure relationship in friction-stir welds is primarily governed by the weld thermal cycle.

\section{Data availability statement}

The raw/processed data required to reproduce these findings cannot be shared at this time due to technical or time limitations.

\section{Declaration of Competing Interest}

The authors declare that they have no known competing financial interests or personal relationships that could have appeared to influence the work reported in this paper.

\section{Acknowledgments}

This study was financially supported by the Russian Science Foundation (grant No. 19-49-02001). The authors also would like to thank the personnel of the Joint Research Center "Technology and Materials" at Belgorod State National Research University for experimental assistance.

\section{Appendix A. Supplementary data}

Supplementary data to this article can be found online at https://doi. org/10.1016/j.matchar.2021.111202.

\section{References}

[1] R.S. Mishra, Z.Y. Ma, Friction stir welding and processing, Mater. Sci. Eng. R 50 (2005) 1-78, https://doi.org/10.1016/j.mser.2005.07.001.

[2] P.L. Threadgill, A.J. Leonard, H.R. Shercliff, P.J. Withers, Friction stir welding of aluminum alloys, Int. Mater. Rev. 54 (2009) 49-93, https://doi.org/10.1179/ 174328009 X411136.

[3] X. Meng, Y. Huang, J. Cao, J. Shen, J.F. dos Santos, Recent progress on control strategies for inherent issues in friction stir welding, Prog. Mater. Sci. 115 (2021) 100706, https://doi.org/10.1016/j.pmatsci.2020.100706.

[4] R. Jain, S.K. Pal, S.B. Singh, Finite element simulation of temperature and strain distribution during friction stir welding of AA2024 aluminum alloy, J. Inst. Eng. India Ser. C 98 (2017) 37-43, https://doi.org/10.1007/s40032-016-0304-3.

[5] T. Wu, F. Zhao, H. Luo, H. Wang, Y. Li, Temperature monitoring and material flow characteristics of friction stir welded 2A14-T6 aerospace aluminum alloy, Mater. 12 (2019) 3387, https://doi.org/10.3390/ma12203387.

[6] G. Buffa, J. Hua, R. Shivpuri, L. Fratini, Design of the friction stir welding tool using the continuum based FEM model, Mater. Sci. Eng. A 419 (2006) 381-388, https://doi.org/10.1016/j.msea.2005.09.041.

[7] M. Assidi, L. Fourment, S. Guerdoux, T. Nelson, Friction model for friction stir welding process simulation: calibrations from welding experiments, Int. J. Mach. Tools Manuf. 50 (2010) 143-155, https://doi.org/10.1016/j. ijmachtools. 2009.11.008.

[8] P. Zhang, N. Guo, G. Chen, Q. Meng, C. Dong, L. Zhou, J. Feng, Plastic deformation behavior of the friction stir welded AA2024 aluminum alloy, Int. J. Adv. Manuf. Technol. 74 (2014) 673-679, https://doi.org/10.1007/s00170-014-6031-0.

[9] T. Long, W. Tang, A.P. Reynolds, Process response parameter relationships in aluminium alloy friction stir welds, Sci. Technol. Weld. Join. 12 (2007) 311-317, https://doi.org/10.1179/174329307X197566. 
[10] D.G. Anrade, C. Leitao, N. Dialami, M. Chiumenti, D.C. Rodrigues, Modelling torque and temperature in friction stir welding of aluminum alloys, Int. J. Mech. Sci. 182 (2020) 105725, https://doi.org/10.1016/j.ijmecsci.2020.105725.

[11] G. Chen, Q. Shi, Y. Li, Y. Sun, Q. Dai, J. Jia, Y. Zhu, J. Wu, Computational fluid dynamics studies on heat generation during friction stir welding of aluminum alloy, Comput. Mater. Sci. 79 (2013) 540-546, https://doi.org/10.1016/j. commatsci.2013.07.004.

[12] T. Nakamura, T. Obikawa, I. Nishizaki, M. Enomoto, Z. Fang, Friction stir welding of non-heat-treatable high-strength alloy 5083-O, Metals 8 (2018) 208-224, https://doi.org/10.3390/met8040208.

[13] P.B. Prangnell, J.R. Bowen, P.J. Apps, Ultra-fine grain structures in aluminium alloys by severe plastic deformation processing, Mater. Sci. Eng. A 375-377 (2004) 178-185, https://doi.org/10.1016/j.msea.2003.10.170.

[14] F.J. Humphreys, P.B. Prangnell, J.R. Bowen, A. Gholinia, C. Harris, Developing stable fine-grain structures by large strain deformation, Philos. Trans. R. Soc. Lond A 357 (1999) 1663-1681, https://doi.org/10.1098/rsta.1999.0395.

[15] H. Jazaeri, F.J. Humphreys, The transition from discontinuous to continuous recrystallization in some aluminium alloys I - the deformed state, Acta Mater. 52 (2004) 3239-3250, https://doi.org/10.1016/j.actamat.2004.03.030.

[16] T. Hebesberger, H.P. Stuwe, A. Vorhauer, F. Wetscher, R. Pippan, Structure of Cu deformed by high pressure torsion, Acta Mater. 53 (2005) 393-402, https://doi. org/10.1016/j.actamat.2004.09.043.

[17] T.G. Langdon, The mechanical properties of superplastic materials, Metal. Trans. A 13 (1982) 689-701, https://doi.org/10.1007/BF02642383.

[18] S. Mironov, K. Inagaki, Y.S. Sato, H. Kokawa, Effect of welding temperature on microstructure of friction-stir welded aluminum alloy 1050, Metal. Mater. Trans. A 46 (2015) 783-790, https://doi.org/10.1007/s11221-014-2651-0.

[19] J. Jeon, S. Mironov, Y.S. Sato, H. Kokawa, S.H.C. Park, S. Hirano, Friction-stir spot welding of single crystal austenitic stainless steel, Acta Mater. 59 (2011) 7439-7449, https://doi.org/10.1016/j.actamat.2011.09.013.
[20] S. Mironov, K. Inagaki, Y.S. Sato, H. Kokawa, Microstructural evolution of pure copper during friction-stir welding, Philos. Mag. 95 (2015) 367-381. https://doi. org/10.1080/14786435.2015.1006293.

[21] Y. Huang, Y. Xie, X. Meng, J. Li, Atypical grain coarsening of friction stir welded AA6082-T6: characterization and modeling, Mater. Sci. Eng. A 740-741 (2019) 211-217, https://doi.org/10.1016/j.msea.2018.10.109.

[22] P.B. Prangnell, C.P. Heason, Grain structure formation during friction stir welding observed by the stop action technique, Acta Mater. 53 (2005) 3179-3192, https:// doi.org/10.1016/j.actamat.2005.03.044.

[23] J.-Q. Su, T.W. Nelson, T.R. McNelley, R.S. Mishra, Development of nanocrystalline structure in Cu during friction stir processing (FSP), Mater. Sci. Eng. A 528 (2011) 5458-5464, https://doi.org/10.1016/j.msea.2011.03.043.

[24] U.F.H.R. Suhuddin, S. Mironov, Y.S. Sato, H. Kokawa, Grain structure and texture evolution during friction stir welding of thin 6016 aluminum alloy sheets, Mater. Sci. Eng. A 527 (2010) 1962-1969. https://doi.org/10.1016/j.msea.2009.11.029.

[25] D. Yi, S. Mironov, Y.S. Sato, H. Kokawa, Effect of cooling rate on microstructure of friction-stir welded AA1100 aluminum alloy, Philos. Mag. 96 (2016) 1965-1977, https://doi.org/10.1080/14786435.2016.1185186.

[26] A. Kalinenko, K. Kim, I. Vysotskiy, I. Zuiko, S. Malopheyev, S. Mironov, R. Kaibyshev, Microstructure-strength relationship in friction-stir welded 6061-T6 aluminum alloy, Mater. Sci. Eng. A 793 (2020) 139858, https://doi.org/10.1016/j. msea.2020.139858.

[27] F.J. Humphreys, Quantitative metallography by electron backscattered diffraction, J. Microsc. 195 (1999) 170-185, https://doi.org/10.1046/j.13652818.1999.00578.x.

[28] R.W. Fonda, J.F. Bingert, K.J. Colligan, Development of grain structure during friction stir welding, Scr. Mater. 51 (2004) 243-248, https://doi.org/10.1016/j. scriptamat.2004.04.017.

[29] R.W. Fonda, K.E. Knipling, Texture development in friction stir welds, Sci. Technol. Weld. Join. 16 (2011) 288-294, https://doi.org/10.1179/ 1362171811Y.0000000010. 